\title{
Life table methods applied to use of medical care and of prescription drugs in early childhood
}

\author{
FINN RASMUSSEN ${ }^{1}$ AND BJÖ RN SMEDBY ${ }^{2}$ \\ From ${ }^{1}$ the Department of Social Medicine and ${ }^{2}$ the Centre for Primary Care Research, Uppsala University, Sweden.
}

ABSTRACT Life table methods were applied to analyses of longitudinal data on the use of medical care during the first 5 years of life among all 1701 children born in a Swedish semirural municipality. Cumulative proportions of the children who had used particular types of medical care or prescription drugs at least once by certain ages were estimated. By the fifth birthday, $98 \%$ had made at least one visit to any physician and $82 \%$ at least one visit to a paediatrician. By the fifth birthday at least one prescription for antibiotics had been purchased at a pharmacy by $82 \%$; and $33 \%$ had been admitted to inpatient hospital care at least once (excluding immediate postnatal care). Acute conditions and more chronic diseases were also studied using these methods. At least one visit to a physician at a primary health care centre had been made for acute otitis media in $65 \%$ of 5 year olds and for atopic dermatitis in $8 \%$.

Most studies of the use of health care by children are cross sectional, refer to selected groups of individuals or consider only some parts of the health services. To understand how patterns of health care utilisation develop during the first dynamic years of life, longitudinal studies are needed. ${ }^{1-3}$

The general objective of this study was to apply life table methods to longitudinal data on the use of medical care and prescription drugs by children. The patterns of utilisation of medical care obtained by these methods are, of course, very different from the patterns obtained by studying the total utilisation (eg, the number of physician visits) during a defined time period. The specific objectives were to study the proportions of children who had used particular types of medical care (or prescription drugs) at least once by certain ages.

\section{Methods}

THE HEALTH CARE SETTING IN TIERP

The research setting is a municipality, Tierp, located in mideastern Sweden about $60 \mathrm{~km}$ (37 miles) north of the city of Uppsala. The size of the population has been about 21000 during the last two decades. About two thirds of the population live in small towns or villages and about one third live in rural areas.

Primary health care is concentrated on a health centre where family physicians and some physicians under training in family medicine work together with several specialists. The health centre has had a paediatrician working full time since 1975. An otorhinolaryngologist has worked continuously at the health centre at least one day per week since 1980 and 0 an ophthalmologist has worked there two days per week since 1978. During the study years about 2808 physicians worked at the health centre, in many cases as a part of their rotating internship or residency in family medicine. Visits to specialists were most often? made after a referral from a family physician or a physician under training. Most specialised outpatient care and all inpatient care was provided at the hospitals in the city of Uppsala.

Prescribed drugs as well as over-the-counter drugs can be purchased at two pharmacies in the community of Tierp and at three smaller branch outlets in different parts of the municipality.

In Sweden the child health centres are important sources of health care for young families. All mothers are invited to the local child health centre by a district nurse for at least nine routine health examinations of their children and to a physician for at least three examinations during the first year of life. Thereafter and up to school age they are invited to at least one visit per year. These visits are free of charge and are attended by about $99 \%$ during the first year of life. Minor health problems are often discussed and treated at these routine health examinations. Between the routine visits, the district nurse is often contacted for young children's health problems and will make home visits if necessary.

THE CHILDREN

The study population comprised all children born 
from 1973 to 1980 in Tierp, totalling 1701. The children were identified in the County Civic Population Register which is updated continuously and contains the civic identification number, the age and gender of all individuals in the area. Information about migration is contained in the register but to ensure the exact date of migration additional information was collected from all parish offices in the municipality.

Among the 1701 children, $96 \%$ were still living in the Tierp municipality at their first birthday, $92 \%$ at their second, $88 \%$ at their third and $84 \%$ at their fifth birthday. Four children died during their first year of life. All other losses to follow up were due to migration.

\section{DATA ON USE OF MEDICAL CARE}

The Tierp municipality has been a setting for primary care research since $1972 .{ }^{4-6}$ As part of the research activities, visits to physicians and purchases of prescribed drugs had been prospectively recorded.

For the present study, information was used about visits to physicians made at the Tierp health centre from 1975 to 1985 , including the civic identification number of the patient, the date of visit, type of physician and diagnoses according to the Swedish version of a Nordic classification for ambulatory care diagnoses. ${ }^{7}$ Diagnoses were assigned by the physician immediately after the visit. One main diagnosis should always be given but one or two secondary diagnoses could also be assigned. The main diagnosis as well as secondary diagnoses were used in this study. A validity study showed that the proportion of physician visits in the patient records not found in the register was so small that this error could be neglected. ${ }^{4}$

Register information on visits to physicians made at three hospitals in Uppsala and to private physicians from 1977 to 1985 was also used. Most of these visits were made at the large university hospital and the register from this hospital included the date of the visit and type of department, but not the diagnosis.

The register information from the department of paediatrics at this hospital was validated for a random sample of 100 children born between 1977 and 1980 , drawn from all individuals born in Tierp during these years. According to the hospital records, $95 \%$ of the first visits to a physician made by these children were also found in the register, with a date of visit differing by no more than one day from the date recorded in the records (sensitivity). For $97 \%$ of the children who, according to their records, had made no visit at the department of paediatrics, no visit was found in the register (specificity). The records of the 100 children were also scrutinised for data on all diagnoses assigned at outpatient physician visits or during inpatient hospital care at the department of paediatrics the first
5 years of life. These data were used in estimating by how much the proportions of children visiting physicians for certain specified diagnoses were underestimated when calculations were based on data only from the Tierp health centre.

Visits to the outpatient departments of two smaller hospitals and to private physicians in Uppsala were covered by the research register only if the patients had claimed reimbursement for travel expenses at the local social insurance office.

Data on all inpatient hospital care at the large university hospital were obtained from another register containing information on the type of department and the date of admission.

No register information on the visits to the nine child health centres in the study area was available. Collecting such information would have been very time consuming and not worth the effort, since the quality of retrospective data on reasons for contacts with these centres for medical care would be questionable. Another reason for not collecting such data was that the emphasis of this study was on diseases for which most parents would find it necessary to seek a physician or a hospital outpatient department.

\section{DATA ON USE OF PRESCRIBED DRUGS}

Information about all prescribed drugs purchased at the two pharmacies in Tierp from 1973 to 1984, including the patient's civic identification number, date of prescription and a pharmaceutical code ${ }^{8}$ were used. The register also included drugs prescribed at the child health centres if purchased at the pharmacies in Tierp. Each item on a prescription form was recorded separately. Some drugs, such as certain cough and cold medicines, laxatives, iron preparations, vitamins, antipyretic analgesics and ointments, were sold over the counter during the study years. The over-thecounter drugs could, however, also be purchased as prescription drugs, which resulted in price reduction. Some pharmaceutical groups thus include over the counter drugs as well as prescription drugs. Other pharmaceutical groups include prescription drugs only.

Some prescribed drugs may have been purchased at pharmacies in Uppsala, eg, after visits to physicians at the hospitals in Uppsala. A methodological study carried out during one week in 1980 showed that the number of prescription drug purchases made by the Tierp population (of all ages) at the pharmacies in Uppsala was about $5 \%$ of the total number of such purchases made by the same population during the same period.

STATISTICAL METHODS

The starting point of an observation period was the 
date of birth and the end point was the date of the first physician visit (any visit, or the first visit for a certain specified diagnosis), the first purchase of a prescribed drug (any drug, or a specified type of drug) or the first hospital admission. Five year follow up periods were used. Some children died or moved from the Tierp municipality before the termination of the study and before the considered type of medical care had been used. These children are censored cases and were included in the analyses from the date of birth to the date of migration or death.

Cumulative proportions of children with at least one drug prescription, at least one physician visit and at least one hospital admission were estimated by the product-limit and the actuarial life table methods. ${ }^{9}$ The actuarial method was used in the analysis shown in the tables and the product limit method in the analyses shown in the figures. Life tables for males and females were compared for statistically significant differences by the generalised Wilcoxon statistic. ${ }^{9}$ The "lifetest" procedure in SAS ${ }^{10}$ and the life tables and survival functions (P1L) in BMDP were used in the analyses. $^{11}$

\section{Results}

\section{PHYSICIAN VISITS}

At least one visit to any physician (with the exception of physician visits at the child health centres) was made by $48 \%$ during the first 6 months of life, by $74 \%$ during the first year and by $98 \%$ during the first 5 years (table 1). At the first birthday, one or more physician visits had been made at the primary health care centre by $61 \%$ and at a hospital outpatient department by $39 \%$ of the children. At least one visit to any paediatrician (excluding visits at the child health centres) was made by $50 \%$ during the first year and by $82 \%$ during the first 5 years of life (fig 1 ). By the fifth birthday, $78 \%$ had visited a paediatrician at the Tierp health centre and $39 \%$ had visited a paediatrician at the hospital outpatient department in Uppsala. Only $2 \%$ of the children in Tierp had visited a private physician before their fifth birthday. The last column in the tables shows the proportion of children censored because they had moved from the Tierp municipality or died before the termination of the study and before the specified type of medical care had been used.

Table 2 shows the proportions of children visiting a physician at least once at the Tierp health centre for particular diagnoses, both acute conditions and chronic diseases. By the first birthday, one or more physician visits had been made for acute otitis media by $19 \%$ and for secretory otitis media by $1 \%$. By the fifth birthday, one or more visits for acute otitis media had been made by $65 \%$ and for secretory otitis media by $20 \%$. One or more visits for acute upper respiratory tract infection had been made by $30 \%$ by the first birthday and by $63 \%$ by the fifth birthday.

During the first 5 years of life one or more visits for injuries or poisonings had been made by $47 \%\left(53 \% \frac{\mathrm{D}}{\overrightarrow{\mathrm{d}}} \overrightarrow{\mathrm{O}}\right.$ boys, $41 \%$ girls, $\mathrm{p}<0.001$ ). During the same period $\stackrel{9}{\circ}$ one or more visits for wounds, contusions or $\stackrel{2}{2}$ superficial injuries were made by $31 \%$ (38\% boys, $24 \%$ girls, $\mathrm{p}<0.0001$ ).

By the fifth birthday 3\% had made at least one visit for bronchial asthma. One or more visits for atopic dermatitis had been made by $8 \%$ of the children during the first five years of life (table 2, fig 2).

\section{INPATIENT HOSPITAL CARE}

By the first birthday, 33\% had been admitted at least once to inpatient care at any hospital department and $31 \%$ to the department of paediatrics (table 1, fig 1).

Table 1 Cumulative proportions of children with at least one physician visit, at least one prescription drug purchase or at least one hospital admission during the first 5 years of life, by source of service

\begin{tabular}{|c|c|c|c|c|c|c|c|c|}
\hline \multirow[b]{2}{*}{ Type and source of service } & \multirow{2}{*}{$\begin{array}{l}\text { Birth cohort } \\
\text { (year of birth) }\end{array}$} & \multirow{2}{*}{$\begin{array}{l}\text { Number of } \\
\text { children }\end{array}$} & \multicolumn{5}{|c|}{ Follow up time in years of life } & \multirow{2}{*}{$\begin{array}{l}\text { Proportion } \\
\text { censored at the } \\
\text { fifth birthday }\end{array}$} \\
\hline & & & 0.5 & $1 \cdot 0$ & $2 \cdot 0$ & $3 \cdot 0$ & $5 \cdot 0$ & \\
\hline Any physician visit & $77-80$ & 805 & 0.48 & 0.74 & 0.90 & 0.94 & 0.98 & 0.03 \\
\hline $\begin{array}{l}\text { Any physician visit at the Tierp } \\
\text { health centre }\end{array}$ & $75-80$ & 1211 & $0 \cdot 29$ & 0.61 & 0.83 & 0.90 & 0.96 & 0.04 \\
\hline Paediatrician & $76-80$ & 987 & 0.16 & 0.36 & 0.56 & 0.67 & 0.78 & 0.08 \\
\hline $\begin{array}{l}\text { Family physicians and physicians } \\
\text { under training }\end{array}$ & $75-80$ & 1211 & $0 \cdot 14$ & 0.34 & 0.46 & 0.50 & 0.53 & $0 \cdot 12$ \\
\hline Any physician visit at hospital & $77-80$ & 805 & 0.27 & 0.39 & 0.49 & 0.53 & 0.65 & 0.09 \\
\hline Department of paediatrics & $77-80$ & 805 & 0.18 & 0.27 & 0.33 & 0.36 & 0.39 & 0.11 \\
\hline Visits to private physicians & $77-80$ & 805 & 0.01 & 0.01 & 0.01 & 0.02 & 0.02 & $0 \cdot 15$ \\
\hline Any prescription drug & $73-79$ & 1497 & 0.47 & 0.71 & 0.87 & 0.91 & 0.95 & 0.04 \\
\hline All inpatient care & $75-80$ & 1211 & 0.30 & 0.33 & 0.38 & 0.40 & 0.44 & 0.09 \\
\hline Department of paediatrics & $75-80$ & 1211 & 0.28 & 0.31 & 0.34 & 0.35 & 0.37 & $0 \cdot 10$ \\
\hline $\begin{array}{l}\text { Any physician visit, drug prescription } \\
\text { or hospital admission }\end{array}$ & $77-80$ & 805 & 0.70 & 0.86 & 0.95 & 0.98 & 0.99 & 0.00 \\
\hline
\end{tabular}




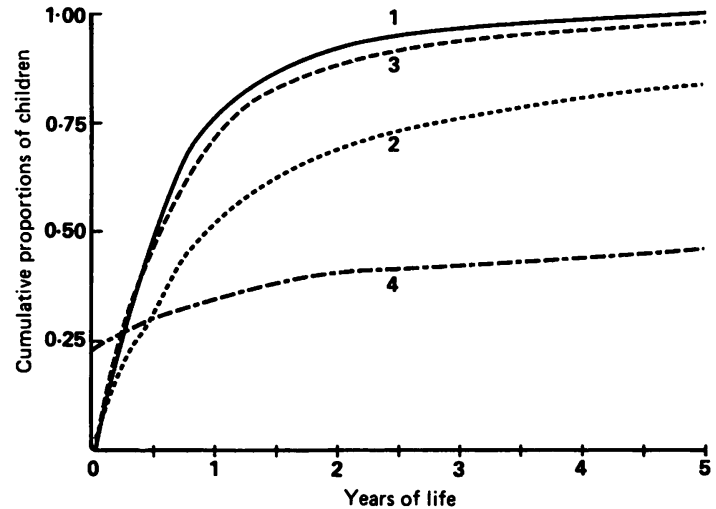

Fig 1 Cumulative proportions of children with at least one visit to any physician (1), to a paediatrician (2), and at least one purchase of any prescribed drug (3), and at least one admission to inpatient care at any hospital department (4).

Twenty five percent of the children were referred from the department of obstetrics to the department of paediatrics within the first 7 days of life, in most cases for observation after caesarean section, jaundice, difficulties in controlling body temperature, or being small for gestational age or of low birth weight. Most of these children had only minor symptoms and were discharged after a few days. By the fifth birthday $44 \%$ and $37 \%$ had been inpatients at any hospital department and at the department of paediatrics respectively.

Analyses were also made after exclusion of inpatient care episodes in which both admission and discharge occurred within the first 7 days of life. These analyses showed that $33 \%$ of the 1211 children had been admitted to any hospital department during the first 5 years of life and that $24 \%$ had been inpatients in the department of paediatrics during the same period.

\section{PRESCRIPTION DRUGS}

One or more prescription drugs had been purchased for $47 \%$ during the first 6 months, for $71 \%$ during the first year and for $95 \%$ of the children during the first 5 years of life (table 3). At least one purchase of an antibiotic drug had been made for $31 \%$ at the first birthday and for $82 \%$ at the fifth birthday. Nasal decongestants for topical use, in most cases the sympathomimetics xylometazoline and oxymetazoline, had been purchased for $47 \%$ at the first birthday and for $72 \%$ at the third birthday. A prescription was necessary for purchases of nasal decongestants up to 1981. After that year some of these drugs could be purchased without a prescription. Alterations were made in the Swedish pharmaceutical code in 1978, and for these technical reasons the use of topical nasal decongestants were analysed only for the first 3 years of life among the children born from 1973 to 1974.

Among the 1497 children born from 1973 to 1979 , $10 \%$ had received prescriptions for neuroleptic drugs by their fifth birthday. These primarily antipsychotic drugs have sedative and hypnotic effects in the low dosage usually prescribed for children.

By the fifth birthday, prescriptions for bronchodilators had been purchased for $47 \%$ and dermatological corticosteroids for $32 \%$ of the children. From 1983 some mild dermatological corticosteroids could be purchased without a

Table 2 Cumulative proportions of 1211 children born from 1975 to 1980 with at least one visit to a physician at the Tierp health centre during the first 5 years of life, by diagnosis

\begin{tabular}{|c|c|c|c|c|c|c|}
\hline \multirow[b]{2}{*}{ Diagnosis (see text) } & \multicolumn{5}{|c|}{ Follow up time in years of life } & \multirow{2}{*}{$\begin{array}{l}\text { Proportion } \\
\text { censored at the } \\
\text { fifth birthday }\end{array}$} \\
\hline & 0.5 & 1.0 & $2 \cdot 0$ & $3 \cdot 0$ & $5 \cdot 0$ & \\
\hline Infectious gastroenteritis & 0.02 & 0.05 & 0.11 & 0.14 & 0.18 & $0 \cdot 14$ \\
\hline Disease of the eye & 0.02 & 0.05 & 0.09 & $0 \cdot 12$ & $0 \cdot 18$ & 0.14 \\
\hline Conjunctivitis & 0.01 & 0.04 & 0.07 & 0.09 & 0.13 & $0 \cdot 14$ \\
\hline Acute otitis media or secretory otitis media & 0.03 & $0 \cdot 19$ & 0.39 & 0.51 & 0.66 & $0 \cdot 10$ \\
\hline Acute upper respiratory tract infection & $0 \cdot 10$ & $0 \cdot 30$ & 0.44 & 0.51 & 0.63 & 0.09 \\
\hline Acute tonsilitis (including scarlet fever) & 0.00 & 0.03 & 0.09 & $0 \cdot 15$ & 0.29 & $0 \cdot 14$ \\
\hline Pneumonia & 0.00 & 0.01 & 0.03 & 0.05 & 0.09 & $0 \cdot 15$ \\
\hline Bronchial asthma & 0.00 & 0.01 & 0.01 & 0.02 & 0.03 & $0 \cdot 15$ \\
\hline Infection of urinary tract & 0.01 & 0.01 & 0.02 & 0.05 & $0 \cdot 10$ & 0.15 \\
\hline Disease of the skin & 0.02 & 0.06 & 0.14 & $0 \cdot 19$ & $0 \cdot 27$ & $0 \cdot 13$ \\
\hline Atopic dermatitis & 0.00 & 0.01 & 0.04 & 0.06 & 0.08 & $0 \cdot 15$ \\
\hline Injury or poisoning & 0.01 & 0.05 & $0 \cdot 18$ & $0 \cdot 29$ & 0.47 & 0.12 \\
\hline Wound, contusion or superficial injury & 0.00 & 0.02 & $0 \cdot 10$ & $0 \cdot 17$ & 0.31 & 0.13 \\
\hline All physician visits with a diagnosis & 0.29 & 0.61 & 0.82 & 0.90 & 0.96 & 0.04 \\
\hline
\end{tabular}




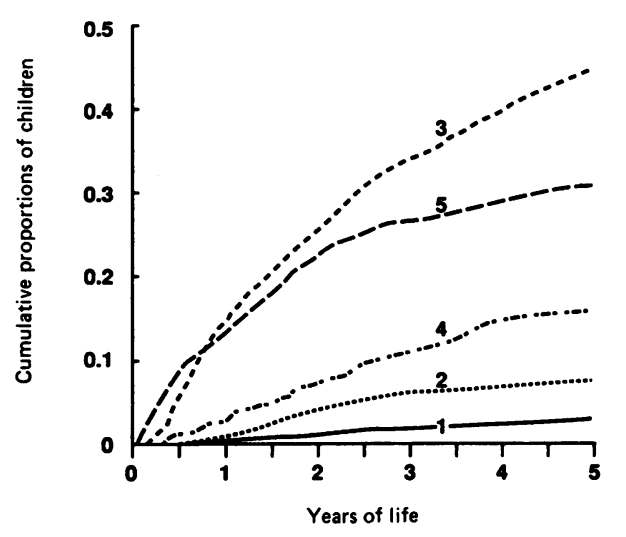

Fig 2 Cumulative proportions of children with at least one physician visit at Tierp health centre for wheezy bronchitis or bronchial asthma (1), atopic dermatitis (2), and cumulative proportions with at least one purchase of bronchodilators (3), systemic antihistamines (4) and dermatological corticosteroids (5).

prescription. Before that year a prescription was required for all dermatological corticosteroids (table 3 , fig 2).

Seventeen percent had received at least one prescription for systemic antihistamines during the first 5 years of life. The pharmaceutical code was changed in 1976 and promethazine moved from the group of hypnotics and sedatives to the systemic antihistamines. In all calculations promethazine has been transferred to systemic antihistamines and for technical reasons this group of drugs was analysed only among the 414 children born from 1978 to 1979 . Only a few systemic antihistamines could be purchased without a prescription.

\section{Discussion}

The socio-economic structure of the population and health care resources in the study area are comparable to a large number of other semirural municipalities in Sweden but conclusions for the whole country cannot, of course, be based solely on this study.

The use of medical care and prescribed drugs among the children of families who had moved from the municipality were not studied after the date of migration. Small numbers of children migrated from the municipality during the follow up periods. The proportions of censored cases were always below the proportions migrating and were lowest for the most common events. Since the proportions of censored individuals were low, there is no reason to believe that the results are biased by migration.

The fact that only $2 \%$ of the children had made no visits to a physician at the fifth birthday may indicate the existence of a group of very healthy children or a group whose parents do not call in a physician when their children become ill. This figure may, of course, also partly reflect limitations of the registers.

In a previous study it was shown that the register information about physician visits at the Tierp health centre was nearly complete. ${ }^{4}$ This study showed that the validity of the information from the register at the department of paediatrics in Uppsala was reasonably good. Outpatient visits at the two smaller hospitals

Table 3 Cumulative proportions of children with at least one prescription drug purchase during the first 5 years of life by pharmaceutical group

\begin{tabular}{|c|c|c|c|c|c|c|c|c|}
\hline \multirow[b]{2}{*}{ Pharmaceutical group (see text) } & \multirow{2}{*}{$\begin{array}{l}\text { Birth cohort } \\
\text { (year of birth) }\end{array}$} & \multirow{2}{*}{$\begin{array}{l}\text { Number of } \\
\text { children }\end{array}$} & \multicolumn{5}{|c|}{ Follow up time in years of life } & \multirow{2}{*}{$\begin{array}{l}\text { Proportion } \\
\text { censored at the } \\
\text { fifth birthday }\end{array}$} \\
\hline & & & 0.5 & 1.0 & $2 \cdot 0$ & $3 \cdot 0$ & $5 \cdot 0$ & \\
\hline Respiratory system drugs & $73-79$ & 1497 & $0 \cdot 12$ & 0.28 & 0.43 & 0.52 & 0.65 & $0 \cdot 10$ \\
\hline Antitussives and expectorants & $73-79$ & 1497 & 0.07 & 0.18 & 0.29 & 0.35 & 0.44 & 0.12 \\
\hline Bronchodilators* & $73-79$ & 1497 & 0.06 & 0.15 & $0 \cdot 26$ & $0 \cdot 34$ & 0.47 & $0 \cdot 12$ \\
\hline Systemic antihistamines & $78-79$ & 414 & 0.02 & 0.03 & 0.07 & $0 \cdot 11$ & 0.17 & 0.15 \\
\hline Alimentary tract drugs & 73-79 & 1497 & 0.07 & 0.08 & $0 \cdot 10$ & 0.11 & $0 \cdot 14$ & 0.15 \\
\hline Antibiotics* & $73-79$ & 1497 & 0.09 & $0 \cdot 31$ & 0.53 & 0.67 & 0.82 & 0.09 \\
\hline Central nervous system drugs & $73-79$ & 1497 & 0.01 & 0.05 & 0.09 & 0.10 & $0 \cdot 11$ & $0 \cdot 16$ \\
\hline Hypnotics and sedatives & $73-79$ & 1497 & 0.002 & 0.01 & 0.02 & 0.02 & 0.02 & 0.16 \\
\hline Neuroleptics* & $73-79$ & 1497 & 0.01 & 0.05 & 0.08 & 0.09 & $0 \cdot 10$ & 0.16 \\
\hline Antipyretic analgesics & $73-79$ & 1497 & 0.02 & 0.08 & $0 \cdot 16$ & 0.21 & 0.29 & 0.14 \\
\hline Ophthalmologicals & $73-79$ & 1497 & 0.07 & 0.11 & $0 \cdot 16$ & 0.20 & 0.27 & 0.14 \\
\hline Dermatologicals & 73-79 & 1497 & 0.13 & $0 \cdot 21$ & $0 \cdot 33$ & 0.39 & 0.47 & $0 \cdot 12$ \\
\hline Dermatological corticosteroids & $73-79$ & 1497 & 0.08 & 0.13 & $0 \cdot 23$ & 0.27 & 0.32 & 0.13 \\
\hline All prescription drugs & $73-79$ & 1497 & 0.47 & 0.71 & 0.87 & 0.91 & 0.95 & 0.04 \\
\hline
\end{tabular}

- Pharmaceutical groups including prescription drugs only 
and to private practitioners in Uppsala were, however, underestimated. Based on the authors' personal knowledge about medical services in the county, the visits made by the studied children to these small hospitals and to private practitioners amounted, in any case, to a very small part of their total use of physician visits.

It is a limitation that no information about the use of medical care at the child health centres was included. The intention was, however, to study use of medical care for diseases for which most parents would find it necessary to seek a physician or a hospital department, rather than the minor illnesses for which many parents would rely on self care or consult the child health centre.

In a Swedish study from the city of Malmö made during the late 1970 s, $55 \%$ of 2191 children had made at least one physician visit for acute otitis media by their fourth birthday. ${ }^{13}$ Among the 1211 children from Tierp the corresponding proportion with 95 percent confidence interval (CI) was 57 (54-60)\%. The Malmö study was based on otoscopically diagnosed cases reported on special forms by many physicians. These similarities in the methods used for collecting the data increased the comparability even though life table methods were not applied in the Malmö study. The validity study referred to previously, including data on diagnoses from outpatient and inpatient hospital care at the department of paediatrics in Uppsala in addition to diagnoses from the Tierp health centre, showed that $57(47-67) \%$ of the 100 children had made one or more visits for acute otitis media during the first 4 years of life. These comparisons suggest that the proportions of children with acute otitis media estimated from the Tierp health centre data were correct.

The Tierp study confirmed the well known sex differences in relation to injury or poisoning, with more boys than girls being affected. It is noteworthy that clear sex differences also occur during the first years of life. ${ }^{12}$ Evidently the sex difference with respect to accidents persists in spite of all efforts in society towards an equal upbringing for males and females.

Eight per cent $(95 \% \mathrm{CI}, 6-10 \%)$ had made at least one physician visit in the Tierp health centre for atopic dermatitis during the first 5 years. The corresponding number for the 100 children in the validity study was also $8(3-13) \%$ suggesting that the estimate for atopic dermatitis from the main study seems to be correct. Some children with mild atopic dermatitis might, however, have received treatment only at child health centres, or the parents might have relied on self care. Peters and Golding reported that $12 \%$ of the children in a large British cohort had developed childhood eczema before the age of 5 years. ${ }^{14}$ That study, which was based on interview information collected from the mothers, may have included a greater number of mild cases compared with the Tierp study.

Among the 1211 children, $3(2-4) \%$ had made at least one physician visit for asthma at the Tierp health centre during the first 5 years. The corresponding figure from the validity study, which yielded additional diagnostic information, was $8(3-13) \%$. Because of the wide confidence limits, conclusions regarding asthma should be made cautiously. The true prevalence of asthma is difficult to determine due to uncertainties regarding the definition of the disease. The prevalence in various populations of children range from $2-10 \% .{ }^{15}$ Reasonably, some of the children with asthma received all their medical care for this diagnosis at the department of paediatrics in Uppsala.

By the fifth birthday, one or more bronchodilators had been purchased for $47 \%$, while only $3 \%$ of the children had visited a physician at the Tierp health centre for asthma. The underestimation of the proportion of children with asthma only explains a small part of this discrepancy but there are other possible explanations. Due to limitations of the diagnostic code list, visits to physicians for wheezy bronchitis-another reason for prescribing bronchodilators-could not be counted with reasonable accuracy and are therefore not presented in this paper. Furthermore, the pharmaceutical group of bronchodilators includes some expectorants containing ephedrine intended for cough with some degree of bronchial obstruction. Lastly, some selective $\beta_{2}$ receptor stimulating drugs were prescribed for whooping cough and for severe unspecified cough in accordance with the prevailing therapeutic practice during the study years. Eight per cent of the children in this study had made a visit to a physician for whooping cough at the Tierp health centre during the first 5 years of life.

The present results showed that neuroleptic drugs had been purchased for $10 \%$ and hypnotics and sedatives for $2 \%$ of the children during the first 5 years. Nearly all the individuals with purchases of neuroleptics had received alimemazine (Theralene ${ }^{\circledR}$ ). In many cases this drug was presumably prescribed for itching as part of a skin disease or for sleeping problems or conduct disorders. Other analyses of our own data from the Tierp municipality showed that purchases of hypnotics or sedatives were made for $3 \%$ of $0-4$ year olds in 1973 and for $0.6 \%$ of $0-4$ year olds in 1983. Correspondingly, neuroleptics were purchased for $2 \%$ of the $0-4$ year olds both in 1973 and in 1983. The decrease in the population of children with purchases of hypnotics and sedatives were apparently not followed by an increase in the proportions with purchases of neuroleptics. 
Life table methods give information only on the first event of a particular type. These methods are therefore not appropriate for studying the total use of medical care. As shown in the examples in this study, life table methods can, however, be used for describing the dynamics of the first use of particular types of medical care and the first use of medical care for both acute conditions and more chronic diseases.

The authors are indebted to Karin Wengelin for help with programming and grateful to Ragnar Berfenstam, Tony Foucard and Claes Sundelin for valuable criticism. The authors are also grateful to Karin Hokkanen Koen who reviewed the English language. This study was supported by a grant from the Committee on Rational Use of Drugs of the National Corporation of the Swedish Pharmacies.

Address for correspondence and reprints: Finn Rasmussen, Dr Med Sc, Department of Social Medicine, Akademiska sjukhuset, S-751 85 Uppsala, Sweden.

\section{References}

${ }^{1}$ Fergusson DM, Horwood LJ, Shannon FT. Social and family factors in childhood hospital admission. $J$ Epidemiol Community Health 1986; 40: 50-8.

2 van Weel C, van den Bosch WJHM, van den Hoogen HJM, Smits AJA. Development of respiratory illness in childhood-a longitudinal study in general practice. $J \boldsymbol{R}$ Coll Gen Pract 1987; 37: 404-8.

${ }^{3}$ Rasmussen F. Use of antibiotics and prescription drugs in general during the first nine years of life in a Swedish community. Paediatr Perinatal Epidemiol 1988; 2: 346-59.
${ }^{4}$ Haglund B. Vilka får sjukvård? En statistisk och kartografisk studie av vårdutnyttjande $\mathrm{i}$ Uppsala län (Health care for whom? A statistical and cartographic study of the health care utilization in the county of Uppsala). Uppsala, Sweden: Acta Universitatis Upsaliensis: Uppsala Dissertations from the Faculty of Medicine 1: 1986. (English summary).

${ }^{5}$ Isacson D. Heavy use of prescription drugs. Pharmacoepidemiological studies in a Swedish community (Dissertation). Uppsala, Sweden: University of Uppsala, 1987.

${ }^{6}$ Rasmussen F, Smedby B. Visits to physicians and prescribed drugs among young children and their mothers. Scan J Prim Health Care 1987; 5: 225-31.

${ }^{7}$ Nordic Medico-Statistical Committee. Code-list for diagnoses used in ambulatory care. Based on the International Classification of Diseases (8th Revision). Stockholm: Nordic Medico-Statistical Committee, 1976.

${ }^{8}$ Läkemedelsinformation AB. FASS 1983 Farmacevtiska specialiteter $i$ Sverige. (Pharmaceutical specialities in Sweden.) Uppsala, Sweden: Almqvist \& Wiksell, 1983.

${ }^{9}$ Kalbfleisch JD, Prentice RL. The statistical analysis of failure time data. New York: John Wiley, 1980.

${ }^{10}$ SAS Institute Inc. SAS user's guide: Statistics, 1985 edition. North Carolina: SAS Institute Inc, 1985.

${ }^{11}$ BMDP statistical software manual. Los Angeles: University of California Press, 1985.

12 Wadsworth J, Burnell I, Taylor B, Butler N. Family type and accidents in preschool children. $J$ Epidemiol Community Health 1983; 37: 100-4.

${ }^{13}$ Lundgren K, Ingvarsson L. Epidemiology of acute otitis media in children. Scand J Infect Dis (Suppl) 1983; 39: 19-25.

14 Peters TJ, Golding J. The epidemiology of childhood eczema: II. Statistical analyses to identify independent early predictors. Paediatr Perinatal Epidemiol 1987; 1: $80-94$.

${ }^{15}$ Foucard T. The wheezy child. Acta Paediatr Scand 1985; 74: $172-8$.

Accepted for publication December 1988 